\title{
The Impact of Self-Criticism and Self- Reassurance on Weight-Related Affect and Well-Being in Participants of a Commercial Weight Management Programme
}

\author{
Cristiana Duarte $^{a} \quad$ James Stubbs $^{b}$ José Pinto-Gouveia ${ }^{a}$ Marcela Matos $^{a}$ \\ Corinne Gale $^{c}$ Liam Morris ${ }^{d}$ Paul Gilbert ${ }^{c}$ \\ ${ }^{a}$ Cognitive and Behavioural Centre for Research and Intervention (CINEICC), Faculty of \\ Psychology and Educational Sciences, Coimbra, Portugal; ${ }^{b}$ Appetite Control and Energy \\ Balance Research Group, School of Psychology, University of Leeds, Leeds, UK; ${ }^{c}$ Mental \\ Health Research Unit, Kingsway Hospital, Derby, UK; Nutrition and Research Department, \\ Slimming World, Alfreton, UK
}

\section{Key Words}

Obesity · Overweight $\cdot$ Psychological aspects $\cdot$ Weight regulation $\cdot$ Well-being

\begin{abstract}
Objective: Certain psychological and emotional factors can undermine attempts at weight management. Previously we have found that shame and self-criticism were significantly associated with disinhibition and perceived hunger in 2,236 participants of a weight management programme. This effect was fully mediated through weight-related negative affect. The present study examined the impact of self-criticism and self-reassurance on well-being and whether it was mediated by weight-related affect in the same population. Methods: Participants completed an online survey of measures of self-criticism and self-reassurance, and negative and positive affect associated with weight and well-being. Results: Path analysis suggested that self-criticism was significantly associated with decreased well-being, both directly and indirectly, mediated by increased negative and decreased positive weight-related affect. Self-reassurance had a stronger association with increased well-being by predicting lower negative and increased positive weight-related affect. All effects were significant at $p$ $<0.001$. Conclusion: Self-criticism and self-reassurance were related to well-being in participants attempting to manage their weight, both directly and through their impact on weightrelated affect. The positive association between self-reassurance and well-being was stronger than the negative association between self-criticism and well-being. Supporting the development of self-reassuring competencies in weight management programmes may improve weight-related affect and well-being.

(C) 2017 The Author(s)

Published by S. Karger $\mathrm{GmbH}$, Freiburg
\end{abstract}

Cristiana Duarte

CINEICC, Faculdade de Psicologia e Ciências da Educação

Universidade de Coimbra

Rua do Colégio Novo, Apartado 6153, 3001-802 Coimbra, Portugal

cristianaoduarte@gmail.com 
Duarte et al.: The Impact of Self-Criticism and Self-Reassurance on Weight-Related Affect and Well-Being in Participants of a Commercial Weight Management Programme

\section{Introduction}

Overweight and obesity are among the greatest societal challenges to health and wellbeing, affecting more than half of the adult population [1]. Obesity has detrimental effects on psychological well-being and is associated with increased morbidity, mortality and greater health care expenditure [2-5]. Governments are calling for the public to take more responsibility for their own health by adopting healthier lifestyles through changes in eating behaviour and becoming more active $[6,7]$. However, translating the ostensibly simple principles of effective weight management into practice to achieve population-level changes in healthrelated behaviours seems to be difficult [8].

Evidence now suggests that sustained weight loss requires behavioural strategies of selfregulation, action planning, developing self-efficacy, autonomy and motivation [9-13]. However, self-management of eating and activity can be undermined by a number of psychological and emotional factors [14]. Attempting to lose weight can create stress by putting motivations and emotions at odds with both physiological drives to defend against energy deficits and environmental cues to overeat $[15,16]$. Overweight and obese people commonly experience stigma, which can increase psychosocial stress and negatively impact on physical and mental well-being $[17,18]$. Believing oneself to be part of a stigmatized group can stimulate unfavourable social comparisons, creating feelings of inferiority and inadequacy and self-criticism [19]. There is evidence that internalization of stigma is associated with overeating. Puhl, Moss-Racusin and Schwartz [20] found that overweight and obese individuals who internalize stigmatized stereotypes, and thus have negative views of themselves, may be more likely to binge eat and less likely to diet in response to stigma. This process could be counterproductive to self-regulation of eating behaviours and motivation to lose weight [20]. Our previous study is also consistent with these findings [21].

Developing a self-reassuring and accepting attitude towards one's imperfections and flaws (e.g., physical appearance) may buffer against the pervasive negative effects of shame, unfavourable social comparisons and body image dissatisfaction [22-24]. Self-critical versus self-reassuring responses to difficult situations during weight management attempts may be important in aligning emotion regulation to benefit self-regulation [25]. Recent relapse prevention models [26-28] now include third-wave psychotherapeutic approaches (e.g., Acceptance and Commitment Therapy [29], Mindfulness-Based Cognitive Therapy [30] and Compassion-Focused Therapy (CFT) [31]) because there is growing evidence that learning to accept and manage emotional responses to stresses associated with relapse can create opportunities for behavioural self-regulation [32-37]. Self-regulation of behaviour for weight management may be supported by strategies that promote stress management and emotion regulation inter alia through self-reassuring compassionate abilities $[8,18$, 23, 33-35, 38-40]. Third-generation behavioural approaches seek to help individuals change their relationship to difficult thoughts, emotions or bodily sensations, rather than trying to change or control them, while engaging in adaptive actions towards effective and sustained behavioural change and well-being [41]. In particular, CFT aims to help individuals to cope with negative self-evaluations, shame and self-criticism through the cultivation of self-reassuring and compassion skills. CFT encourages the development of compassion motivation and engagement with adaptive behaviours with the goal of improving well-being [31].

Many individuals enter weight loss regimes with cycles of early success followed by relapse, which can be associated with a sense of failure, inefficacy, shame and self-criticism $[42,43]$. The recent NICE guidance on managing overweight and obesity in adults emphasizes that lifestyle weight management services should protect people's physical and mental wellbeing [44]. Furthermore, NICE highlights the need for lifestyle weight management 
Duarte et al.: The Impact of Self-Criticism and Self-Reassurance on Weight-Related Affect and Well-Being in Participants of a Commercial Weight Management Programme

programmes to address 'psychological issues, such as body confidence or attitude, depression, anxiety or self-esteem' and 'wider lifestyle factors such as sleeping patterns and stress management'. Few studies of weight management programmes have examined how selfevaluative processes, and the emotion regulation linked to them, impact on well-being. Wellbeing is a multidimensional, dynamic phenomenon that includes not just the absence of physical and mental illness but a subjective sense of happiness, satisfaction with life, positive psychological functioning, a perception of being connected to and accepted by others and of self-realization [45, 46]. Some authors have suggested that improvement of psychological well-being may be central to the long-term effectiveness of weight management programmes $[47,48]$.

Recent work has revealed that the processes of negative and positive self-evaluation, such as self-criticism versus self-reassurance, are not bipolar constructs or mirror images of each other. For example, Körner and colleagues [49] found that positive versus negative selfevaluations had contrasting effects on depression in a large population sample, with negative self-evaluation being the primary predictor of depression. Indeed, studies of positive and negative affect $[50,51]$ indicate that positive affect and well-being, in contrast to negative affect and psychopathology, should perhaps be studied separately. There is also evidence that self-criticism and self-reassuring are associated with different brain systems [52]. This suggests that, in overweight and obese individuals, self-criticism and self-reassurance relationship to outcomes such as well-being may be mediated differently by factors such as weight-related affect. Hence the current study examined the relationships between self-criticism versus self-reassurance and well-being as mediated by positive versus negative weightrelated affect in 2,236 female participants of a weight management programme.

\section{Participants and Methods}

\section{Participants}

Participants $(\mathrm{N}=2,236)$ were female subjects of a community-based weight management programme, which is an open programme of no fixed duration. They were individually engaged in the programme for varying lengths of time and lost differing amounts of weight. Mean (standard deviation; SD) age was 41.71 (12.34) years, height 1.65 (6.71) m, weight 95.61 (18.73) kg and mean BMI was $35.28(6.49) \mathrm{kg} / \mathrm{m}^{2} .19 \%$ had a BMI of $25-29.9 \mathrm{~kg} / \mathrm{m}^{2}, 33.5 \%$ of $30-34.9 \mathrm{~kg} / \mathrm{m}^{2}, 23 \%$ of $35-39.99 \mathrm{~kg} / \mathrm{m}^{2}$, and $24.4 \%$ above $40 \mathrm{~kg} / \mathrm{m}^{2}$. The mean (SD) of the time taken to reach survey since joining the programme was 274.44 (388.76) days. Since starting the programme and the point of survey, 2055 (91.9\%) of the participants lost weight, 27 (1.2\%) gained weight, and $7(0.3 \%)$ maintained weight (no weight data was obtained from 147 participants); BMI change mean (SD) was $-3.68(3.22) \mathrm{kg} / \mathrm{m}^{2}$.

\section{Measures}

Weight-Focused Self-Criticising/Self-Reassuring Scale (WFSCRS)

This 22-item scale is derived from the Forms of Self-Criticising/Attacking and Self-Reassuring Scale (FSCRS) [25]. The FSCRS assesses people's typical responses when things go wrong for them in terms of whether they are self-critical or self-reassuring. In the WFSCRS, the instructions of the measure were adapted to focus on the dimensions of weight, body shape and eating. Participants rate each statement on a 5-point scale $(0=$ 'Not at all like me' to $4=$ 'Extremely like me'). The self-criticism scale has been found to have two subscales: i) inadequate self, which is a sense of feeling internally put-down and inadequate (e.g., 'I can't accept failures and setbacks without feeling inadequate'), ii) hated self, which is a sense of self-dislike and aggressive/persecutory desires to hurt the self (e.g., 'I have become so angry with myself that I want to hurt or injury myself'). In contrast to being self-critical, people can be reassuring of themselves in these contexts. Reassured self is an ability to be encouraging and supportive for self when things go wrong (e.g., 'I am gentle and supportive with myself'). The original scale has good reliability with Cronbach's alphas of 0.90 for inad- 
Duarte et al.: The Impact of Self-Criticism and Self-Reassurance on Weight-Related Affect and Well-Being in Participants of a Commercial Weight Management

Programme

Table 1. Mean (M), standard deviation (SD), Cronbach's alpha ( $\alpha$ ) and Pearson correlation coefficients between the study variables $(\mathrm{N}=2,236)$

\begin{tabular}{lllllllll}
\hline & M & SD & $\alpha$ & $\begin{array}{l}\text { 1 WFFSCRS } \\
\text { self-criticism }\end{array}$ & $\begin{array}{l}\text { 2 WFFSCRS } \\
\text { self-reassurance }\end{array}$ & $\begin{array}{l}3 \text { WFFS } \\
\text { negative affect }\end{array}$ & $\begin{array}{l}4 \text { WFFS } \\
\text { positive affect }\end{array}$ & $\begin{array}{l}5 \text { WEMWBS } \\
\text { well-being }\end{array}$ \\
\hline 1 & 23.82 & 11.70 & 0.91 & 1 & & & & \\
2 & 16.38 & 6.31 & 0.84 & $-0.55^{* * *}$ & 1 & & & \\
3 & 12.64 & 8.37 & 0.88 & $0.77^{* * *}$ & $-0.55^{* * *}$ & 1 & $-0.63^{* * *}$ & 1 \\
4 & 5.13 & 3.45 & 0.79 & $-0.58^{* * *}$ & $0.68^{* * *}$ & $-0.58^{* * *}$ & $0.65^{* * *}$ \\
5 & 46.62 & 10.23 & 0.95 & $-0.55^{* * *}$ & $0.62^{* * *}$ & $0.19^{* * *}$ & $-0.11^{* * *}$ & $-0.09^{* * *}$ \\
6 BMI & 35.28 & 6.49 & & $0.18^{* * *}$ & $-0.14^{* * *}$ & 0.10 & \\
\hline
\end{tabular}

WFFSCRS = Weight Focused Forms of Self-Criticising/Self-Reassuring Scale; WFFS = Weight-Focused Feelings Scale; WEMWBS = Warwick-Edinburgh Mental Well-Being Scale.

$* * * \mathrm{p}<0.001$.

equate self, 0.86 for hated self and 0.86 for reassured self [25]. For the purpose of the current study we combined the two self-criticism subscales (inadequate self and hated self) to obtain an overall measure of self-criticism.

Weight-Focused Feelings Scale (WFFS)

This scale includes 11 items. Participants are asked to rate each item, using a 4-point scale $(1=$ 'Not like me' to 4 'Extremely like me'), about their current feelings linked to body weight and shape. This scale includes two subscales: a 3-item subscale that assesses positive weight-focused affect (e.g., 'I am quite happy in myself') and an 8-item subscale that assesses negative weight-focused affect (e.g., 'I feel depressed and down'). This scale presents good psychometric properties, with the negative affect subscale presenting a Cronbach's alpha of 0.88 and the Positive Affect subscale a value of 0.79 [21].

Warwick-Edinburgh Mental Well-Being Scale (WEMWBS)

The WEMWBS is a 14-item scale that was developed to measure subjective well-being and psychological functioning (e.g., 'I've been thinking clearly', 'I've been feeling loved'). Answers are given on a 5-point Likert scale ( $1=$ 'None of the time' to $5=$ 'All of the time') with higher scores indicating higher levels of mental wellbeing. This scale presents good psychometric properties, including good construct validity, test-retest reliability and internal consistency, with a Cronbach's alpha of 0.91 in the general population [53].

\section{Height and Weight}

Height was self-reported to the nearest $0.5 \mathrm{~cm}$. Participants were weighed in light clothing on scales with a precision of $\pm 0.23 \mathrm{~kg}$ (SECA bespoke model). Accuracy is ensured by calibration against standard weights during routine service, and scales are checked for notable drift weekly in use. The same calibrated scales were used each week at a given group to record weight and weight change. Weights reported for the time of survey were $<10$ days of the survey date.

The means, SDs and Cronbach's alpha estimates of the measures used in the current study are reported in table 1.

\section{Procedure}

Slimming World is a national lifestyle-based weight management organization that provides communitybased group support for about 800,000 members in regular attendance at any one time who are seeking to manage their weight and to develop healthy eating and activity behaviours. The organization delivers a community-based behaviour change support programme for weight loss, via networks of local classes, 4,000 group leaders and support staff, written, online and multimedia resources, eating plans, diet models and evidence-based behaviour change techniques promoting whole-diet approaches to weight management and gradual increases in physical activity [54-56]. 
Duarte et al.: The Impact of Self-Criticism and Self-Reassurance on Weight-Related Affect and Well-Being in Participants of a Commercial Weight Management Programme

This study was approved by the University of Derby Ethics Committee, and was advertised on the Slimming World members' website. The advertorial directed participants to a website designed specifically for this project, which provided detailed information about the study and contact details for the research team to answer any specific questions about the study. Those wishing to voluntarily participate were asked to indicate their consent by clicking the appropriate button on the website. Participants were offered the opportunity to enter a prize draw for one of five gift vouchers (each worth GBP 100.00) as a 'thank you' for their voluntary participation. Once consent had been obtained, participants were directed to a link to the self-report questionnaires, which were completed online. The questionnaire (available on request) consisted of questions in which the participant selected drop-down menus to describe their age, height, level of activity, date of birth, duration of membership, time taken to reach current weight and time at current weight. Data on employment status, ethnicity and socioeconomic status were not collected in this survey. However, data from a larger audit of participants of this programme suggest that their socioeconomic characteristics reflect the Index of Multiple Deprivation score distributions of the general UK population (within 1-3\% across all 5 quintiles) [57]. The remainder of the questionnaire took the form of Likert-type scales, asking questions about self-criticism and self-reassurance in relation to weight, negative and positive affect related to weight, and mental well-being as described above. The questionnaire took approximately $30 \mathrm{~min}$ to complete. Data was collected over a period of 6 weeks.

\section{Data Analysis}

Pearson correlation coefficients were calculated to explore the correlations between the study variables. Data analyses were conducted using SPSS (v. 21; IBM Corporation, Armonk, NY, USA). A path analysis was conducted to explore the indirect effect of self-evaluation (weight-focused self-criticism/self-reassurance) on well-being through weight-focused positive and negative affect, using the software SPSS AMOS (v. 21; Analysis of Moment Structures; IBM Corporation). The path analysis aimed to determine whether weight-focused positive and negative affect (mediators, measured by the WFFS), would contribute for the association between self-criticism and self-reassurance, as measured by WFSCRS (exogenous variables) and well-being as measured by WEMWBS (dependent, endogenous variable). Path analyses are a subset of Structural Equation Modelling (SEM), used to assess theoretically expected causal relations between previously defined variables, testing for direct and indirect effects between exogenous and endogenous variables, while controlling for error [58]. The Maximum Likelihood method was used to evaluate the regression coefficients' significance. The significance of direct, indirect and total effects was assessed using chi-square tests. Bootstrap resampling was further used to test for the significance of the mediation paths by selecting 2,000 bootstrap samples and $95 \%$ bias-corrected confidence intervals (CIs). Effects were considered significantly different from zero $(\mathrm{p}<0.05)$ when zero was outside the interval between the lower and the upper $95 \%$ bias-corrected confidence intervals.

\section{Results}

\section{Descriptive Statistics and Correlations}

Descriptive statistics and Cronbach's alphas for the study variables are presented in table 1.

Product-moment Pearson correlation results indicated that weight-focused self-criticism was strongly and negatively associated with self-reassurance, weight-related positive affect and mental well-being. Self-criticism showed a strong positive association with weight-related negative affect. Conversely, weight-related self-reassurance showed a strong positive association with weight-related positive affect and with overall mental well-being. Weight-related negative affect was strongly and negatively associated with well-being, while weight-related positive affect was strongly and positively associated with well-being. Smaller but significant associations were found between higher BMI and increased self-criticism and weight-related negative affect, and lower self-reassurance, weight-related positive affect and well-being. 


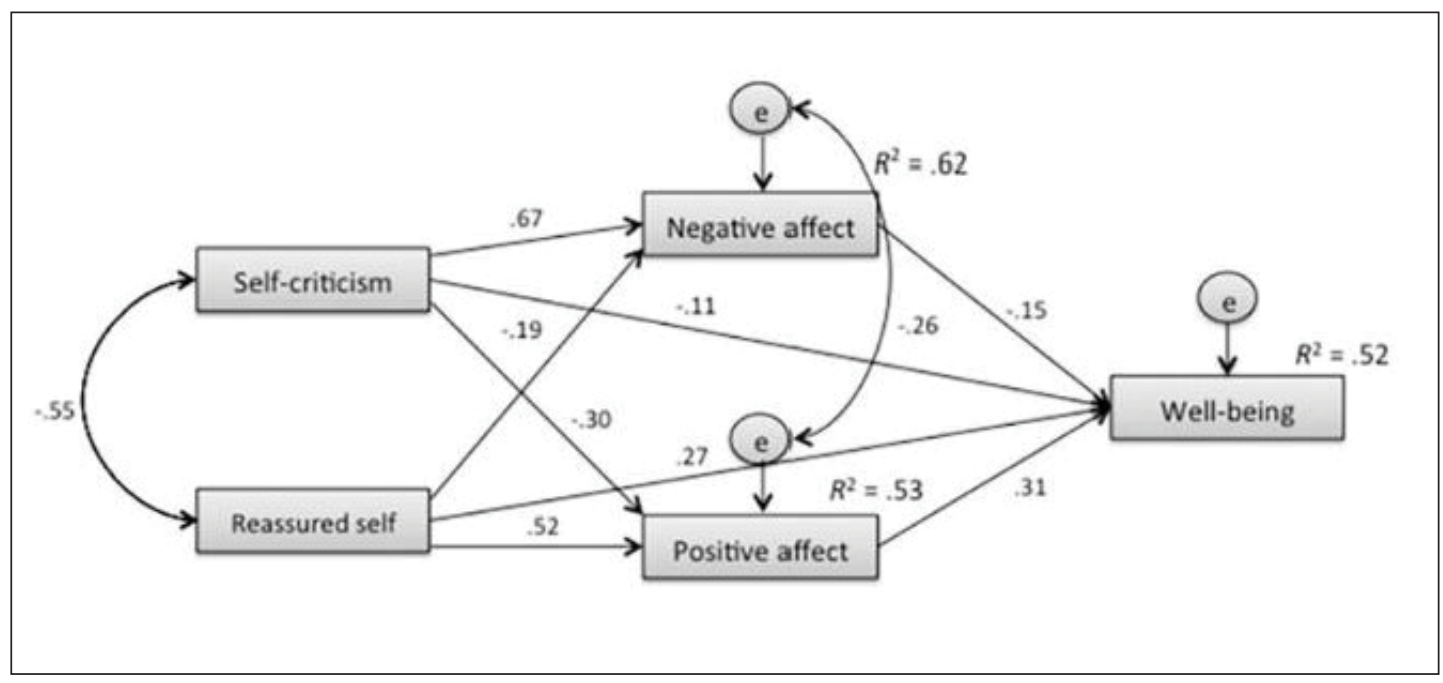

Fig. 1. Graphic representation of the path model showing the association between self-criticism and reassured self, and well-being, mediated by negative and positive weight-focused affect, with standardized estimates and square multiple correlations $\left(R^{2}\right)$. All effects were significant $(p<0.001)$.

\section{Path Analysis}

Data was screened for uni-and multivariate normality, Skewness (which varied from -0.04 WEMWBS to 0.42 WFFS Negative Affect) and Kurtosis (values ranged from -0.03 WEMWBS to -0.94 WFFS Positive Affect). There was no violation of normal distribution [58].

The model tested for the indirect effect of weight-focused self-criticism and self-reassurance on well-being, through the mechanism of weight-related negative and positive affect (fig. 1). The hypothesized model included 23 parameters to be estimated. The sample size (N $=2,236$ ) was ideal to conduct the analysis considering the model's complexity (according to the $\mathrm{N}$ :q rule of $20: 1$ [59]).

All the paths were statistically significant. The model accounted for a $52 \%$ of variance in well-being. Self-criticism and self-reassurance accounted for $62 \%$ of negative and for $53 \%$ of positive affect related to weight. Self-criticism and self-reassurance were significantly and moderately negatively correlated (-0.55). Self-criticism had a direct effect of $0.67\left(b_{\text {Self-criticism }}\right.$ $=0.48, \mathrm{SE} b=0.01, Z=43.42, \mathrm{p}<0.001$ ) on negative affect related to weight, but a smaller direct effect on positive affect related to weight of $-0.30\left(b_{\text {Self-criticism }}=-0.09, \mathrm{SE} b=0.01, Z=\right.$ $-17.09, \mathrm{p}<0.001$ ). Conversely self-reassurance positively predicted positive feelings about weight, with a direct effect of $0.52\left(b_{\text {Reassured self }}=0.29, \mathrm{SE} b=0.01, Z=30.11, \mathrm{p}<0.001\right)$, and negatively predicted negative affect, with a direct effect -0.19 ( $b_{\text {Reassured self }}=-0.25$, SE $b=$ $0.021, Z=-12.02, \mathrm{p}<0.001)$. Weight-related negative affect had a direct negative effect of -0.15 on well-being; $\left(b_{\text {Negative affect }}=-0.18, \mathrm{SE} b=0.03, Z=-5.90, \mathrm{p}<0.001\right)$. Positive affect had a direct positive effect of 0.31 on well-being; $\left(b_{\text {Positive affect }}=0.93, \mathrm{SE} b=0.07, Z=14.12, \mathrm{p}<\right.$ 0.001 ).

Regarding mediation effects, self-criticism significantly decreased well-being, with a total effect of -0.27 , a direct effect of -0.11 ( $b_{\text {Self-criticism }}=-0.10, \mathrm{SE} b=0.02, Z=-4.64, \mathrm{p}<0.001$ ) and an indirect effect of -0.19 , mediated by increased levels of negative weight-related feelings, and by decreased levels of positive feelings about one's weight. These effects were statistically significant according to the bootstrap resampling method $(95 \% \mathrm{CI}=-0.23$ to $-0.16 ; \mathrm{p}=0.001$ ). 
Duarte et al.: The Impact of Self-Criticism and Self-Reassurance on Weight-Related Affect and Well-Being in Participants of a Commercial Weight Management

Programme

Self-reassurance had a higher predictive effect on well-being than did self-criticism, with a positive total effect of 0.46 and a direct effect of 0.27 ; $b_{\text {Reassured self }}=0.43, \mathrm{SE} b=0.03, Z=$ $12.70, \mathrm{p}<0.001)$. Self-reassurance also had a significant indirect effect of $0.19(95 \% \mathrm{CI}=$ $0.16-0.22 ; \mathrm{p}=0.001$ ) on well-being, mediated by lower negative and increased weight-related positive affect.

\section{Discussion}

There is a large body of evidence showing that self-criticism has a negative effect on mental health and well-being $[25,60]$. A recent study revealed that self-criticism is associated with shame, negative self-perceptions and emotions related to weight, which has a negative association with self-regulation of eating behaviours [21]. However, as noted in our introduction, research has also revealed that positive and negative self-evaluation are not bipolar constructs or mirror images of each other but need to be studied separately. Hence, this study explored the relationship between the negative and positive emotion-based self-evaluative dimensions, weight-related self-criticism and self-reassurance, and well-being in participants of a weight-management organization using a mediation model predicting subjective well-being. The model used self-criticism versus self-reassurance as predictors, and negative versus positive weight-related affect as mediators of the primary outcome (well-being).

Looking first at the correlations, results showed that self-criticism and self-reassurance were indeed negatively correlated but the correlation was not sufficiently high to suggest a bipolar construct. The findings suggested that self-criticism was not inspiring or encouraging but was actually linked to negative feelings about one's weight. In contrast, being self-reassuring was associated with more positive feelings about one's weight. Although small in magnitude, self-criticism and negative affect about one's weight were linked to BMI in a positive direction, whereas being more self-reassuring and positive feelings about one's weight were associated with lower BMI. Future research using prospective/experimental designs should explore these associations further, but the current results may indicate that the heavier the individuals are the more likely they are to belong to a stigmatized social group, internalize negative evaluations of being inferior and engage in self-criticism. This may have negative consequences for self-regulation of eating behaviour and weight, and psychological well-being, promoting a self-sustained cycle.

This is the first study to clearly demonstrate the differential effects of self-criticism and self-reassurance on weight-focused affect or feelings. Our interpretation of the analyses is that being self-critical or self-reassuring of one's weight had contrasting effects on emotions linked to weight, and these relationships, in turn, may have affected well-being. Our results suggested a linkage between increased BMI, self-criticism, weight-focused negative feelings, lower-reassurance and lower well-being. These findings fit with the growing research on how self-criticism fuels negative emotions and undermines mental well-being [21,60], and suggests that distinct forms of self-relating and emotional dimensions of self-evaluation may impact on the well-being of overweight/obese individuals in different ways. These data highlight the potential importance for lifestyle weight management programmes in providing forms of support that promote positive aspects of self-relating and self-evaluation, which may have wider impacts on well-being and body confidence or attitude, depression, anxiety or self-esteem. This is an area for potential further investigation. The findings of the current study are consistent with other studies suggesting that promotion of adaptive emotion regulation and well-being may be important for sustained behavioural change for weight management $[13,47,48]$.

These associations were further examined in the mediation path model, which accounted for $52 \%$ of the variance in well-being. This model suggested that being self-critical versus self- 
Duarte et al.: The Impact of Self-Criticism and Self-Reassurance on Weight-Related Affect and Well-Being in Participants of a Commercial Weight Management

Programme

reassuring were significantly associated with how individuals feel about their body shape, weight and eating. These negative and positive emotional dimensions in turn mediated the association between self-criticism and self-reassurance and overall well-being of respondents attempting to manage their weight. Thus, this research suggested the importance of distinguishing between the psychological processes that undermine well-being and those that promote it. The mediation analysis indicated that these processes interacted but also operated through different specific pathways. Self-criticism was significantly associated with lower well-being; this effect partially depended on the extent to which self-criticism was associated with increased weight-related negative affect, and to a lesser extent, decreased positive affect. On the other hand, being self-reassuring and self-supportive was associated with increased well-being, both directly and partially through increased weight-related positive affect. In other words, self-reassurance presented a significant direct effect on well-being, but its effect also partially operated through weight-related affect, especially positive feelings of happiness and optimism in relation to one's weight. Taken together with a previous analysis [21], this study suggests that in a given weight management programme self-reassuring, supportive approaches may be associated with well-being and self-regulation of eating behaviour.

\section{Limitations of the Present Study}

Although these findings were supported by robust statistical analysis, the cross-sectional design of this study does not allow the establishment of causal conclusions. Future research should investigate through prospective designs how interventions that target self-criticism and self-reassurance impact on well-being during attempted weight management.

The current study used a large sample representative of individuals attending weight management programmes. Nonetheless, participants were predominately middle-aged, Caucasian women. Although approximately $5 \%$ of the regular membership of the commercial weight management organization are male, only $1.8 \%$ of the respondents to the survey were men, and so they were under-represented in this sample and were excluded from the analyses. Future research should include a wider range of sociodemographic groups and genders. As with most surveys of this type, only a small percentage of participants in the programme who had accessed the website actually took part in the survey. The site is accessed by $>100,000$ participants per week (although the number accessing the survey description was not recorded). In a separate online study where participant access was recorded from the same population of participants of a commercial weight management programme, we have found that 10,483 participants accessed a survey, of whom 2,492 completed it. These were relatively successful participants since, on average, they had lost $10.19 \%$ of their initial weight in approximately 9 months prior to the survey. By definition of taking part in the study they were prepared to discuss their emotions in relation to their weight control. It may well be that the variables of interest present differently in those who are less successful participants in weight management programmes.

\section{Conclusions}

In this study of 2,236 female participants of a community-based weight management programme, weight focused self-criticism and self-reassurance were related to well-being in participants attempting to manage their weight, both directly and through their impact on weight-related affect. They were also related to BMI. The positive association between self- 
Duarte et al.: The Impact of Self-Criticism and Self-Reassurance on Weight-Related Affect and Well-Being in Participants of a Commercial Weight Management Programme

reassurance and well-being was greater than the negative association between self-criticism and well-being. These findings suggest that facilitating, supporting and developing self-reassuring competencies in weight management programmes may improve weight-related affect and well-being. In other words, interventions should not just focus on trying to reduce selfcriticism but should actively stimulate self-reassurance and well-being.

\section{Disclosure Statement}

Research by the first author (Cristiana Duarte) is supported by a Ph.D. Grant (SFRH/BD/76858/2011), sponsored by FCT (Portuguese Foundation for Science and Technology). The study was funded by Slimming World. James Stubbs is a Consultant to Slimming World through University of Leeds Consulting (Trading as Consulting Leeds). Liam Morris is employed by Slimming World.

\section{References}

1 World Health Organization: Methodology and summary: Country profiles on nutrition, physical activity and obesity in the 53 WHO European region member states. 2013. www.euro.who.int/en/health-topics/noncommunicable-diseases/obesity (last accessed March 14, 2017).

2 Muller-Riemenschneider F, Reinhold T, Berghofer A, Willich SN: Health-economic burden of obesity in Europe. Eur J Epidemiol 2008;23:499-509.

3 Wang YC, McPherson K, Marsh T, Gortmaker SL, Brown M: Health and economic burden of the projected obesity trends in the USA and the UK. Lancet 2011;378:815-825.

4 Finkelstein EA, Strombotne KL, Popkin BM: The costs of obesity and implications for policymakers. Choices 2010;25. www.choicesmagazine.org/magazine/article.php?article=136 (last accessed March 14, 2017).

5 Yach D, Stuckler D, Brownell K: Epidemiologic and economic consequences of the global epidemics of obesity and diabetes. Nat Med 2006;12:62-66.

6 HM Government: Healthy Lives, Healthy People: Our Strategy for Public Health in England. London, 2010,

7 Office of the Surgeon General (US): The Surgeon General's Vision for a Healthy and Fit Nation. Rockville, 2010. www.ncbi.nlm.nih.gov/books/NBK44660/ (last accessed March 14, 2017)

8 Stubbs RJ, Lavin JH: The challenges of implementing behaviour changes that lead to sustained weight management. Nutr Bull 2013;38:5-22.

9 Dombrowski SU, Avenell A, Sniehotta FF: Behavioural interventions for obese adults with additional risk factors for morbidity: systematic review of effects on behaviour, weight and disease risk factors. Obes Facts 2010;3:377-396

10 Maes S, Karoly P: Self-regulation assessment and intervention in physical health and illness: a review. Applied Psychol 2005;54:267-299.

11 Sniehotta FF, Schwarzer R, Scholz U, Schüz B: Action planning and coping planning for long-term lifestyle change: theory and assessment. Eur J Soc Psychol 2005;35:565-576.

12 Sniehotta FF, Scholz U, Schwarzer R: Bridging the intention-behaviour gap: planning, self-efficacy, and action control in the adoption and maintenance of physical exercise. Psychol Health 2005;20:143-160.

13 Teixeira PJ, Mata J, Williams GC, Gorin AA, Lemieux S: Self-regulation, motivation, and psychosocial factors in weight management. J Obes 2012;2012:582348.

14 Stubbs RJ, Gale C, Whybrow S, Gilbert P: The evolutionary inevitability of obesity in modern society: implications for behavioral solutions to weight control in the general population; in Martinez MP, Robinson H (eds): Obesity and Weight Management: Challenges, Practices and Health Implications, New York, Nova Science Publishers, 2012.

15 Dallman MF, Pecoraro N, Akana SF, La Fleur SE, Gomez F, Houshyar H, Bell ME, Bhatnagar S, Laugero KD, Manalo S: Chronic stress and obesity: a new view of 'comfort food'. Proc Natl Acad Sci U S A 2003;100:1169611701.

16 Block JP, He Y, Zaslavsky AM, Ding L, Ayanian JZ: Psychosocial stress and change in weight among us adults. Am J Epidemiol 2009;170:181-192.

17 Puhl RM, Heuer CA: The stigma of obesity: a review and update. Obesity (Silver Spring) 2009;17:941-964.

18 Puhl RM, Heuer CA: Obesity stigma: Important considerations for public health. Am J Public Health 2010;100: 1019-1028.

19 Ferreira C, Pinto-Gouveia J, Duarte C: Physical appearance as a measure of social ranking: The role of a new scale to understand the relationship between weight and dieting. Clin Psychol Psychot 2013;20:55-66.

20 Puhl R, Moss-Racusin C, Schwartz M: Internalization of weight bias: implications for binge eating and emotional well-being. Obesity (Silver Spring) 2007;15:19-23. 
Duarte et al.: The Impact of Self-Criticism and Self-Reassurance on Weight-Related Affect and Well-Being in Participants of a Commercial Weight Management Programme

21 Duarte C, Matos M, Stubbs RJ, Gale C, Morris L, Gouveia JP,Gilbert P: The impact of shame, self-criticism and social rank on eating behaviours in overweight and obese women participating in a weight management programme. PLoS One 2017;12:e0167571.

22 Ferreira C, Pinto-Gouveia J, Duarte C: The validation of the body image acceptance and action questionnaire: exploring the moderator effect of acceptance on disordered eating. Int J Psychol Psycholl Ther 2011;11:327345.

23 Ferreira C, Pinto-Gouveia J, Duarte C: Self-compassion in the face of shame and body image dissatisfaction: Implications for eating disorders. Eat Behav 2013;14:207-210.

24 Duarte C, Ferreira C, Trindade I, Pinto-Gouveia J: Body image and college women's quality of life: the importance of being self-compassionate. J Health Psychol 2015;20:754-764.

25 Gilbert P, Clarke M, Hempel S, Miles J, Irons C: Criticizing and reassuring oneself: an exploration of forms, styles and reasons in female students. Br J Clin Psychol 2004;43:31-50.

26 Hendershot CS, Witkiewitz K, George WH, Marlatt GA: Relapse prevention for addictive behaviors. Subst Abuse Treat Prev Policy 2011;6:17.

27 Marlatt GA, George WH: Relapse prevention: Introduction and overview of the model. Br J Addict 1984;79: 261-273.

28 Witkiewitz K, Marlatt GA: Relapse prevention for alcohol and drug problems: that was zen, this is tao. Am Psychol 2004;59:224-235.

29 Hayes S, Strosahl KD, Wilson K: Acceptance and Commitment Therapy: An Experiential Approach to Behavior Change. New York, Guilford Press, 1999.

30 Segal ZV, Williams JMG, Teasdale JD: Mindfulness-Based Cognitive Therapy for Depression: A New Approach to Preventing Relapse. New York, Guilford Press, 2002.

31 Gilbert P: Compassion: Conceptualisations, Research and Use in Psychotherapy. New York, Routledge, 2005.

32 Lillis J, Hayes SC, Bunting K, Masuda A: Teaching acceptance and mindfulness to improve the lives of the obese: a preliminary test of a theoretical model. Ann Behav 2009;37:58-69.

33 Forman EM, Butryn ML, Hoffman KL, Herbert JD: An open trial of an acceptance-based behavioral intervention for weight loss. Cogn Behav Pract 2008;16:223-235.

34 Forman EM, Butryn ML, Juarascio AS, Bradley LE, Lowe MR, Herbert JD, Shaw JA: The mind your health project: a randomized controlled trial of an innovative behavioral treatment for obesity. Obesity (Silver Spring) 2013; 21:1119-1126.

35 Niemeier HM, Leahey T, Palm Reed K, Brown RA, Wing RR: An acceptance-based behavioral intervention for weight loss: A pilot study. Behav The 2012;43:427-435.

36 Tapper K, Shaw C, Ilsley J, Hill AJ, Bond FW, Moore L: Exploratory randomised controlled trial of a mindfulnessbased weight loss intervention for women. Appetite 2009;52:396-404.

37 O’Reilly GA, Cook L, Spruijt-Metz D, Black DS: Mindfulness-based interventions for obesity-related eating behaviours: a literature review. Obes Rev 2014;15:453-461.

38 Hayes SC, Strosahl KD, Wilson KG: Acceptance and commitment therapy: The Process and Practice of Mindful Change, 2nd ed. New York, Guilford Press, 2011.

39 Hayes SC, Luoma JB, Bond FW, Masuda A, Lillis J: Acceptance and commitment therapy: model, processes and outcomes. Behav Res Ther 2006;44:1-25.

40 Gilbert P: The origins and nature of compassion focused therapy. Br J Clin Psychol 2014;53:6-41.

41 Hayes S: Acceptance and commitment therapy, relational frame theory, and the third wave of behavioral and cognitive therapies. Behav Ther 2004;35:639-665.

42 Gilbert J, Stubbs J, Gale C, Gilbert P, Dunk L, Thomson L: A qualitative study of the understanding and use of 'compassion focused coping strategies' in people who suffer from serious weight difficulties. J Compassionate Health Care 2014;1.

43 Byrne S: Psychological aspects of weight maintenance and relapse in obesity. J Psychosom Res 2002;53:1029_ 1036.

44 National Institute for Health and Clinical Excellence: Managing Overweight and Obesity in AdultsPublic Health Guidance 532014 www.nice.org.uk/guidance/ph53 (last accessed March 14, 2017).

45 Cowen EL: In pursuit of wellness. Am Psychol 1991;46:404-408.

46 Ryan R, Deci E: On happiness and human potentials: a review of research on hedonic and eudaimonic wellbeing. Annu Rev Psychol 2001;52:141-166.

47 Hill JO, Billington CJ: It's time to start treating obesity. Am J Cardiol 2002;89:969-970.

48 Palmeira AL, Markland DA, Silva MN, Branco TL, Martins SC, Minderico CS, et al: Reciprocal effects among changes in weight, body image, and other psychological factors during behavioral obesity treatment: A mediation analysis. Int J Behav Nutr Phys Act 2009;6:9.

49 Körner A, Coroiu A, Copeland L, Gomez-Garibello C, Albani C, Zenger M, Brähler E: The role of self-compassion in buffering symptoms of depression in the general population. PLoS One 2015;10:e136598.

50 Lamers SM, Westerhof GJ, Glas CA, Bohlmeijer ET: The bidirectional relation between positive mental health and psychopathology in a longitudinal representative panel study. J Posit Psychol. 2015:1-8.

51 Watson D, Clark LA, Carey G: Positive and negative affectivity and their relation to anxiety and depressive disorders. J Abnorm Psychol 1988;97:346-353.

52 Longe O, Maratos FA, Gilbert P, Evans G, Volker F, Rockliff H, Rippon G: Having a word with yourself: neural correlates of self-criticism and self-reassurance. Neuroimage 2010;49:1849-1856. 
Duarte et al:: The Impact of Self-Criticism and Self-Reassurance on Weight-Related Affect and Well-Being in Participants of a Commercial Weight Management

Programme

53 Tennant R, Hiller L, Fishwick R, Platt S, Joseph S, Weich S, Parkinson J, Secker J, Stewart-Brown S: The WarwickEdinburgh Mental Well-Being Scale (WEMWBS): Development and Uk validation. Health Quality Life Outcomes $2007 ; 5$

54 Stubbs J, Brogelli D, Pallister C, Avery A, McConnon A, J. L: Behavioural and motivational factors associated with weight loss and maintenance in a commercial weight management programme. Open Obes J 2012;4: 35-43.

55 Stubbs RJ, Pallister C, Whybrow S, Avery A, Lavin J: Weight outcomes audit for 34,271 adults referred to a primary care/commercial weight management partnership scheme. Obes Facts 2011;4:113-120.

56 Stubbs RJ, Whybrow S, Lavin J: Dietary and lifestyle measures to enhance satiety and weight control. Nutr Bull 2010;35:113-125.

57 Stubbs RJ, Morris L, Pallister C, Horgan G, Lavin JH: Weight outcomes audit in 1.3 million adults during their first 3 months' attendance in a commercial weight management programme. BMC Public Health 2015;10:882.

58 Kline RB: Principles and Practice of Structural Equation Modeling, 2nd ed. New York, The Guilford Press, 2005.

59 Jackson DL: Revisiting sample size and number of parameter estimates: some support for the n:1 hypothesis. Structural Equation Modeling 2003;10:128-141.

60 Gilbert P, Irons C: Focused therapies and compassionate mind training for shame and self-attacking; in Gilbert P (ed): Compassion: Conceptualisations, Research and Use in Psychotherapy. London, Routledge, 2005, pp 263-325. 